\title{
Abnormal Liver Blood Tests: Hepatologist Approach
}

\author{
Miodrag N. Krstića Dragana Mijača Ratko S. Tomaševićb Snežana Lukića \\ Milica Stojković Laloševića Jovan M. Krstićc Tomica Milosavljevićd \\ ${ }^{a}$ Clinic for Gastroenterology and Hepatology, University Clinical Center of Serbia, Medical School, \\ University of Belgrade, Belgrade, Serbia; 'bemun Medical Center, Gastroenterology Department, \\ Medical School, University of Belgrade, Belgrade, Serbia; 'Clinic for Digestive Surgery, Clinical Center of \\ Serbia, Medical School, University of Belgrade, Belgrade, Serbia; Internal medicine, Gastroenterology \\ Euromedic Hospital, Belgrade, Serbia
}

\section{Keywords}

Abnormal liver blood tests . Chronic liver disease .

Hepatocellular carcinoma · Primary liver cancer · Treatment

\section{Abstract}

Background: Available data suggest that the prevalence of chronic liver disease (CLD) and primary liver cancer is rising in Europe and represents a major public health problem. Predictions are showing that these trends will continue to rise in the upcoming years. Summary: Alcohol-related liver disease, nonalcohol fatty liver disease, and viral hepatitis B and hepatitis $C$ are the leading causes of liver cirrhosis and primary liver cancer in Europe. Drug-induced liver injury represents a major cause of acute hepatitis, while liver transplantation is the second most common solid organ transplantation in the world. Patients with CLD have increasing rates of hospitalization, longer hospital stays, and more adverse outcomes compared to the other chronic conditions. Direct targeting of risk factors can prevent complications of advanced liver disease and improve outcome. Patients with CLD should be referred to a hepatologist for assessment of the stage of liver disease, for specific treatment and screening for hepa- tocellular carcinoma. Moreover, patients with unknown etiology of abnormal liver blood tests should be referred to a hepatologist for assessment of liver disease, as well as for prevention and treatment of complications of cirrhosis and/ or portal hypertension. Key Messages: CLD is amenable to prevention and treatment, while disease management strategies need to improve in order to reduce the burden of liver disease and deaths due to end-stage liver diseases.

(c) 2021 S. Karger AG, Basel

\section{Introduction}

Chronic liver disease (CLD) represents an area of clinical priority due to increasing rate of morbidity and mortality. Cirrhosis is the 11th leading cause of death worldwide, while liver disease accounts for 2 million deaths per year globally $[1,2]$. Approximately $14 \%$ of US adults are diagnosed with alcohol use disorders and are at high risk for alcohol-related liver disease (ARLD). Approximately 2 billion adults are obese worldwide, and over 400 million adults have diabetes, both of which are risk factors for nonalcoholic fatty liver disease (NAFLD) [2]. Drug-in- karger@karger.com

www.karger.com/ddi (c) 2021 S. Karger AG, Basel

Karger
Correspondence to:

Miodrag N. Krstic, krstic.miodrag61@gmail.com 
duced liver injury (DILI) represents a major cause of acute hepatitis, while the prevalence of viral hepatitis remains high worldwide. Less common causes of CLD are primary biliary cholangitis, autoimmune hepatitis (AIH), and primary sclerosing cholangitis. Hereditary hemochromatosis is a common genetic disorder affecting 1 in 200 people in Europe and USA, while rare genetic disorders are Wilson's disease and alpha- 1 antitrypsin deficiency. Liver cancer is the 16th most common cause of death. Liver transplantation is the second most common solid organ transplantation in the world [2]. Predictions are showing that trends will continue to rise in the upcoming years, predominantly from increasing rate of NAFLD and ARLD [3,4]. Patients with CLD in comparison with other chronic disorders have increased rates of hospitalization, longer hospital stay, more complications, and more adverse outcomes in general [3]. Disease management models for CLD greatly need to manage the anticipated increase in burden of liver disease and hospitalizations for CLD.

\section{Nonalcoholic Fatty Liver Disease}

NAFLD is the most frequent liver disease in Western Europe and USA, with the prevalence ranging from 17 to $46 \%$ of adults. NAFLD is defined as hepatic fat accumulation in $>5 \%$ of hepatocytes according to histology and can be presented with a spectrum of disease activity from NAFL, early NASH, fibrotic NASH, cirrhosis, and HCC [4].

Patients who have metabolic risk factors (waist circumference $94 / 80 \mathrm{~cm}$ for men/women and/or BMI $>25$ ), arterial hypertension, dyslipidemia, insulin resistance, or diabetes type 2 (T2DM) should be further assessed for NAFLD [5]. NASH and fibrotic NASH are rapidly progressive diseases and are associated with an increased mortality rate in comparison with NAFL. Emerging body of evidence suggests that NAFLD is a multisystemic disease associated with cardiovascular disease (CVD), CKD, T2DM, and reduced mineral density [6]. The most common cause of death in patients with NAFLD is CVD, independent of other metabolic comorbidities [5]. At present, NAFLD with advanced liver fibrosis is the third most common cause of HCC and is considered the second leading indication for HCC-related liver transplantation (LT) [7].

NAFLD is present in $7 \%$ of nonobese individuals (lean NAFLD) [8]. Several genetic polymorphisms on the PNPLA3 gene and TM6SF2 gene have been identified

Abnormal Hepatogram: Hepatologist

View with associated risks for NAFLD and increased risk for HCC, but genotyping is not recommended routinely in clinical practice, so far $[9,10]$.

Patients with NAFLD should be referred for noninvasive diagnostic algorithm to predict NASH and fibrosis and should be evaluated for NAFLD-associated diseases (T2DM, CVD, and dyslipidemia). Patients with inconclusive tests should be referred to a hepatologist for transient elastography. In patients with NASH fibrosis, the final diagnosis should be made by liver biopsy $[4,6]$.

Individuals with NAFLD require reinforcement of lifestyle changes regarding dietary restriction and increase in physical activity with aerobic exercise in combination with resistance training. Pharmacologic therapy should be reserved only for patients with progressive $\mathrm{NASH}$, active NASH, and for early-stage NASH with increased risk of fibrosis (age $>50$ years, T2DM, increased ALT, and MetS) [4]. Current therapy includes pioglitazone, vitamin E, or their combination. Statins can be used to prevent cardiovascular risk, but with no effects on liver disease [11].

\section{Alcohol-Related Liver Disease}

According to the WHO, the highest alcohol-related morbidity and mortality is in Europe, with the mean alcohol consumption of $10.9 \mathrm{~L}$ of pure alcohol per person per year. In the EU, $41 \%$ of the liver deaths are attributed to alcohol. Liver injury due to alcohol depends on several more factors including types of alcohol, duration of exposure, genetic susceptibility, and drinking patterns $[12,13]$. Alcohol screening questionnaires are very helpful and should be done systematically by physicians [14]. The AUDIT (Alcohol Use Disorders Inventory Test) remains the gold standard, as it has good sensitivity and specificity to identify heavy drinkers and explicitly addresses consumption dependence [15]. Shorter version, the AUDIT-C, is reliable for the screening of risky drinking occasions $[16,17]$. The CAGE is an easy-to-use tool to identify severe alcohol dependence, although it appears to be a poor screening questionnaire for heavy drinking [18].

Diagnosis of ARLD can be established upon history of regular alcohol consumption ( $>20 \mathrm{~g} /$ day for women and $>30 \mathrm{~g}$ /day for men), together with the presence of clinical, laboratory, and imaging techniques suggestive of liver injury (ultrasonography, CT, and MR) [13]. Alcoholic hepatitis $(\mathrm{AH})$ is a distinct clinical syndrome characterized by the acute onset and progression of jaundice with or 
Fig. 1. Treatment algorithm in patients with alcoholic hepatitis. $\mathrm{mDF}$, Maddrey discriminant function; LT, liver transplantation.

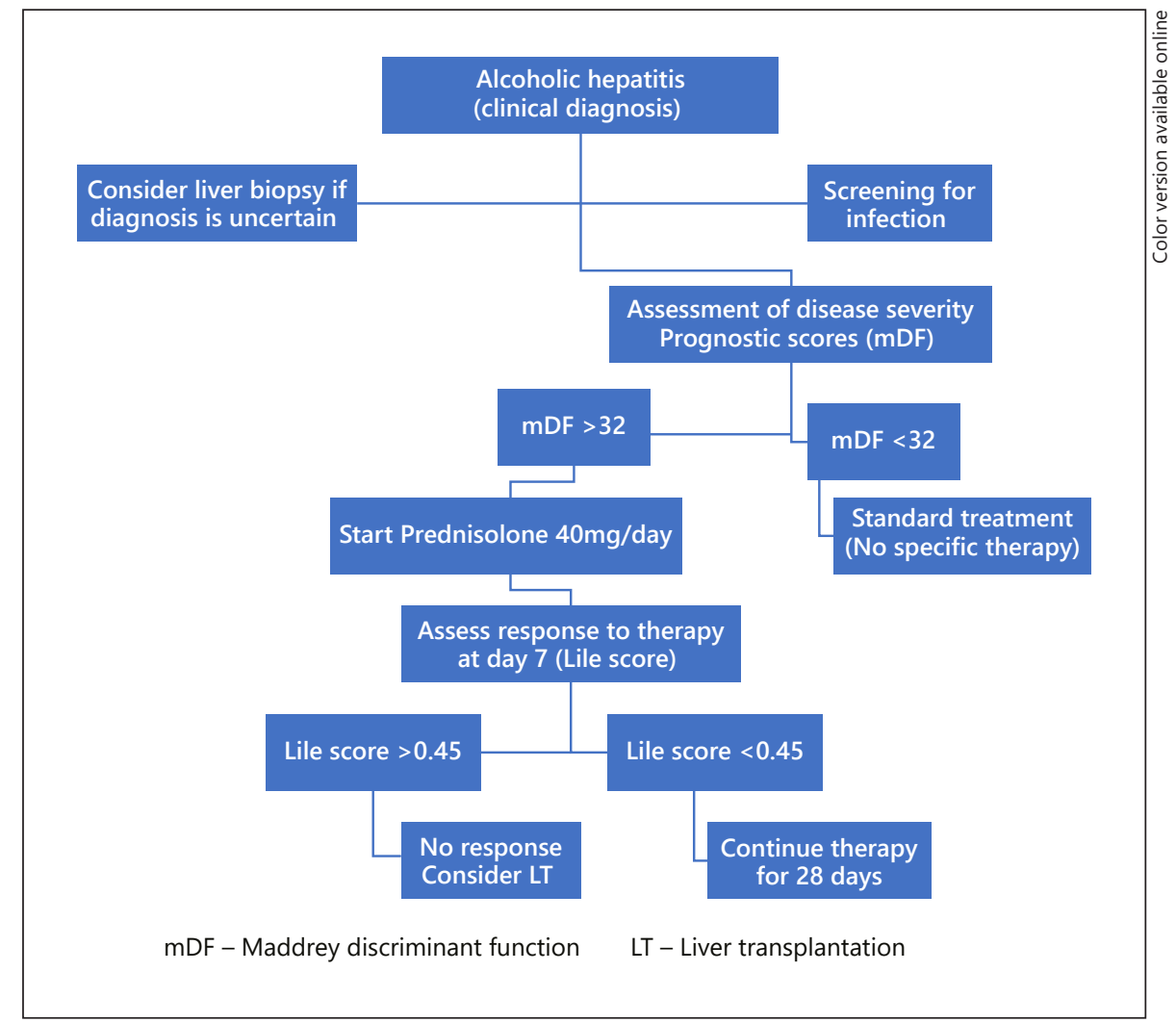

without other signs of liver decompensation (encephalopathy and ascites) in patients with active alcohol abuse [13]. Diagnosis of AH is based on clinical and typical laboratory findings in a patient with a history of recent heavy alcohol use. Early improvements in liver function have a major impact on mortality rate in $\mathrm{AH}$.

The Maddrey score is the most widely used prognostic model for assessment of risk of early death from $\mathrm{AH}$ in the short term [19]. More recently, several prognostic scores have been developed such as MELD (Model for End-Stage Liver Disease) score [20]. Another prognostic score, the Lile model, is based on the response of serum levels of bilirubin to a 7-day treatment of corticosteroid therapy $[21,22]$.

A liver biopsy is reserved for patients where there is diagnostic uncertainty, if there is suspected additional causes of liver injury, to establish the definite diagnosis, to assess the stage of the liver disease, and for prognosis. Approximately $10-20 \%$ of patients with ARLD have coexisting etiology of their liver disease [13].

Therapeutic measures include alcohol abstinence regardless of the stage of the liver disease, adequate nutrition support in malnourished patients (sarcopenia is present in $50 \%$ of patients with advanced ARLD), supplementation with vitamin B complex, treatment of ascites, hepatic encephalopathy (lactulose and rifaximin), and preventive measures of variceal bleeding [13, 23]. Coffee drinking seems to decrease the risk of progression to cirrhosis [24]. Treatment algorithm for patients with $\mathrm{AH}$ is shown in Figure 1.

\section{Hepatitis C Virus Infection}

Hepatitis C virus (HCV) presents one of the most common causes of CLD. It is estimated that 71 million individuals worldwide are infected with HCV [25]. According to the WHO, novel therapies and enhanced improvement in understanding the pathophysiology of $\mathrm{HCV}$ infection make a possible target to eradicate hepatitis $\mathrm{C}$ worldwide in the near future [26].

At least 8 major genotypes of $\mathrm{HCV}$ (each comprising multiple subtypes) have been identified worldwide. HCV genotypes 1,2, and 3 appear to have a worldwide distribution, while the relative prevalence of all genotypes varies from one geographic region to another. 
Table 1. Assessment of patients with chronic HBV infection based on HBV markers and biochemical parameters

\begin{tabular}{lllll}
\hline & HBeAg+ & HBeAg- & HBeAg+ & HBeAg- \\
\hline HBsAg & High & Low & High & Intermediate \\
HBV DNA, IU/mL & $>10^{7}$ & $<2,000$ & $10^{4}-10^{7}$ & $>2,000$ \\
ALT & Normal & Normal & Elevated & Elevated \\
Chronic hepatitis & None/minimal & None & Moderate/severe & Moderate/severe
\end{tabular}

HBV, hepatitis B virus.

The diagnosis is based on presence of anti-HCV antibodies by enzyme immunoassay and detectable $\mathrm{HCV}$ RNA in serum by a sensitive molecular assay with a limit of detection $<15 \mathrm{IU} / \mathrm{mL}$. Anti-HCV antibodies may be undetectable in the early phase of acute infection and in individuals who are immunosuppressed. Severity of liver disease must be assessed prior to treatment. Identifying patients with cirrhosis or advanced fibrosis is important because the specific treatment choice depends on the stage of fibrosis [25].

The primary therapeutic goal is to achieve a sustained virologic response. It is defined as undetectable $\mathrm{HCV}$ RNA after treatment completion (in $<0.2 \%$ of cases, relapse occurs). The combinations of HCV drugs available in Europe are as follows: sofosbuvir, sofosbuvir/velpatasvir, sofosbuvir/velpatasvir/voxilaprevir, glecaprevir/pibrentasvir, and grazoprevir/elbasvir. Treatment with sofosbuvir/velpatasvir and glecaprevir/pibrentasvir can be started without knowledge of the genotype or subtype with high probability of success. In geographical areas (Asia, South America, and Africa) where HCV subtypes inherently resistant to NS5A inhibitors are present, the HCV genotype and subtype should be determined with an assay that can discriminate subtype $1 \mathrm{a}$ from $1 \mathrm{~b}$, if possible [25].

All individuals with HCV infection, who are either treatment naïve or treatment experienced, should be treated without delay. Patients with decompensated cirrhosis with or without an indication for LT should be treated in order to achieve improvement in liver function and survival. For patients awaiting LT, the goal is not only to improve liver function, but also to prevent liver graft infection after LT $[27,28]$.

HCC incidence has dramatically decreased in patients with HCV or HBV infection due to highly effective antiviral therapy $[25,29]$. However, patients with cirrhosis who eradicate their HCV infection remain at substantial risk of HCC. The risk increases with age, advanced chronic disease, cirrhosis, and presence of diabetes.

Abnormal Hepatogram: Hepatologist View
Thus, patients with HCV-induced cirrhosis should be included in follow-up for early detection of liver cancer [29, 30].

\section{Hepatitis B Virus Infection}

Hepatitis B virus (HBV) infection remains still an important global health problem with approximately 240 million people infected worldwide [31]. The highest prevalence is in sub-Saharan Africa and East Asia, where $5-10 \%$ of adult people are chronically infected. Vertical transmission from the infected mother to child - perinatal transmission - leads to chronic disease in $>90 \%$ of newborns in these areas $[31,32]$. On the other hand, the prevalence of $\mathrm{HBV}$ infection is constantly decreasing due to implementation of the vaccination programs worldwide, improvements in the socioeconomic status, and possibly due to effective antiviral treatments [33].

Patients with $\mathrm{HBV}$ infection should be assessed for HBV markers (HBsAg, HBeAg, antiHBe, and HBV DNA) and for liver disease activity and severity (ALT, noninvasive tests of fibrosis-elastography, and/or liver biopsy) in order to identify patients for treatment and HCC surveillance. Serum HBV DNA level is important for the assessment of the phase of the infection, the decision to treat, and follow-up. The assessment of patients with chronic HBV infection is shown in Table 1 . The first-degree relatives and sexual partners of individuals with chronic HBV infection should be tested for HBV serological markers (HBsAg, antiHBs, and antiHBc) and to be vaccinated, if negative [33].

Main treatment strategies of chronic HBV infection include 2 different concepts: therapy with nucleotide analog (NA) or with PEGylated-interferon- $\alpha$ (PEGInf $\alpha$ ). The NA approved in Europe includes NA with low barrier against HBV resistance: lamivudine, adefovir, and telbivudine and NA with high barrier to HBV resistance: entecavir, tenofovir disoproxil fumarate, and tenofovir alafenamide. 
The indication for treatment includes all patients with any detectable HBV DNA $(2,000 \mathrm{IU} / \mathrm{mL})$ and at least moderate liver inflammation, fibrosis, or cirrhosis (compensated or decompensated). Patients with HBV DNA $20,000 \mathrm{IU} / \mathrm{mL}$ and ALT $2 \mathrm{x}$ ULN should also be treated, as well as patients with HBV infection and family history of HCC, cirrhosis, or presence of extrahepatic manifestations of HBV infection [34].

The goal of treatment is the induction of long-term suppression of HBV DNA levels. The loss of HBeAg represents a partial immune control of the chronic HBeAgpositive individuals, while loss of $\mathrm{HBs} A g$ indicates profound suppression of $\mathrm{HBV}$ replication. A biochemical response to treatment is defined as ALT normalization and is usually achieved in patients with long-term suppression of HBV replication. Treatments with potent agents have beneficial effects in liver function, delay the occurrence of hepatic decompensation, and can improve outcomes and survival. HCC in patients with HBV infection is one of the main concerns and can develop in patients with an early stage of $\mathrm{HBV}$ infection or even in individuals who have been effectively treated [35].

\section{Hepatitis E Virus Infection}

Hepatitis E virus (HEV) infection is becoming a new European problem with at least 2 million locally acquired $\mathrm{HEV}$ in Europe, every year. HEV is mostly zoonotic infection with genotype 3 and genotype 4 that primarily spreads through pork meat products and causes silent epidemics in the "Western world." Genotypes 1 and 2 spread through dirty water and mostly cause infection and often deaths in developing parts of the world [36]. Acute infection is usually clinically silent, with $<5 \%$ of patients who develop symptoms such as fatigue, itching with elevated liver enzymes, and jaundice [37]. While immunocompetent patients with acute hepatitis $\mathrm{E}$ can clear the infection spontaneously, immunosuppressed patients may develop a chronic HEV infection. This has been seen only with HEV genotypes 3 and 4 [38].

HEV should be tested in all patients with hepatitis as part of the extended liver blood tests screening, patients presenting with DILI, unexplained flares of CLD, and all immunosuppressed patients with unexplained elevation of LFTs. Proposed diagnostic algorithm should consist of both serology and nucleic acid amplification techniques [39]. Positive laboratory tests that are commonly presented in acute HEV infection are as follows: HEV RNA with or without antiHEV IgM and/or antiHEV IgG or HEV antigen. Positive laboratory tests in chronic HEV infection can be as follows: HEV RNA \pm antiHEV or HEV antigen, while past infection is determined by the presence of antiHEV IgG [36].

Acute HEV infection usually does not require therapy, except for the cases of severe acute hepatitis or acute-onchronic liver failure. In such cases, ribavirin treatment may be considered. In transplant patients, ribavirin monotherapy is the treatment of choice together with reduction of the dose of immunosuppression, if possible. Patients who are nonresponders to ribavirin therapy should be offered PEGInf $\alpha$ for 3 months $[36,40]$.

\section{Autoimmune Hepatitis}

$\mathrm{AIH}$ is a relatively rare progressive, inflammatory CLD. AIH can affect any age, with peaks around puberty and between 40 and 60 years of age, and include both sexes and all ethnic groups. A third of patients are either asymptomatic or have severe acute fulminant hepatitis, while a third of patients already have cirrhosis at the time of diagnosis. Most common symptoms are fatigue, right upper quadrant pain, anorexia, itching, depression, jaundice, and polyarthralgia [41].

AIH is usually characterized by increased IgG levels, in association with human leukocyte antigens DR3 or DR4 and specific circulating autoantibodies. Depending on specific antibodies, it is subclassified into 3 major types: $\mathrm{AIH}$ type 1 (AIH-1) and $\mathrm{AIH}$ type $2(\mathrm{AIH}-2)$ and $\mathrm{AIH}$ type 3 (AIH-3). In AIH-1, antinuclear antibodies and/or smooth muscle autoantibodies are detected, and usually perinuclear anti-neutrophil cytoplasmic antibodies are also found. In AIH-2, specific autoantibodies, namely, anti-liver/kidney microsomal antibody type 1 or rarely anti-LKM type 3 and/or antibodies against liver cytosol type 1 antigen, can be detected. AIH-3 is very similar to AIH-1, with anti-SLA/LP antibodies, often Ro52-antibody is detected [42]. AIH-2 is more frequent in children and young adults, while AIH-1 is typically present in adults. AIH-2 may occur with acute and severe onset with advanced histological lesions at presentation. AIH-3 is similar to AIH-1 but has more severe clinical presentation [43]. Liver biopsy remains a gold standard for the diagnosis.

The first-line therapy is prednisolone in dose $0.5-1$ $\mathrm{mg} / \mathrm{kg} /$ day with azathioprine to a maintenance dose of 1-2 mg/kg/day [44]. Budesonide (9 mg/day) may be considered in noncirrhotic patients with early stage of disease 
Table 2. Phenotypes of DILI and associated medications

\begin{tabular}{|c|c|}
\hline Phenotypes of DILI & Medications \\
\hline Idiosyncratic DILI & $\begin{array}{l}\text { Antibiotics: amoxicillin-clavulanate, erythromycin, flucloxacillin, interferon alpha/peginterferon, isoniazid, ketoconazole, } \\
\text { minocycline, nevirapine, nitrofurantoin, pyrazinamide, rifampicin, co-trimoxazole, and sulfonamides } \\
\text { Central nervous system: carbamazepine, chlorpromazine, dantrolene, halothane, phenytoin, and valproate } \\
\text { Cardiovascular: amiodarone, hydralazine, methyldopa, quinidine, statins (atorvastatin and simvastatin) } \\
\text { Immunomodulatory: azathioprine/6-mercaptopurine, infliximab, interferon beta, methotrexate, and thioguanine } \\
\text { Antineoplastic: busulfan, floxuridine, and flutamide } \\
\text { Rheumatologic: allopurinol, auranofin/gold products, diclofenac, ibuprofen, nimesulide, and sulindac } \\
\text { Endocrine: anabolic androgenic steroids, estrogens/progestins, and propylthiouracil } \\
\text { Others: disulfiram and ticlopidine }\end{array}$ \\
\hline $\begin{array}{l}\text { Drug-induced autoimmune } \\
\text { hepatitis }\end{array}$ & Diclofenac, halothane, indomethacin, infliximab, methyldopa, minocycline, nitrofurantoin, and statins \\
\hline $\begin{array}{l}\text { Secondary sclerosing } \\
\text { cholangitis }\end{array}$ & Amiodarone, atorvastatin, amoxicillin-clavulanate, gabapentin, infliximab, 6-mercaptopurine, sevoflurane, and venlafaxine \\
\hline $\begin{array}{l}\text { Nodular regenerative } \\
\text { hyperplasia }\end{array}$ & $\begin{array}{l}\text { Azathioprine, busulphan, bleomycin, cyclophosphamide, chlorambucil, cysteine arabinoside, carmustine, doxorubicin, } \\
\text { 6-thioguanine, and oxaliplatin }\end{array}$ \\
\hline $\begin{array}{l}\text { Ductopenic (vanishing bile } \\
\text { duct) syndrome }\end{array}$ & $\begin{array}{l}\text { Azathioprine, androgens, amoxicillin-clavulanate, carbamazepine, chlorpromazine, erythromycin, estradiol, flucloxacillin, } \\
\text { phenytoin, terbinafine, and co-trimoxazole }\end{array}$ \\
\hline Liver tumors & Anabolic androgenic steroids and oral contraceptives \\
\hline
\end{tabular}

DILI, drug-induced liver injury.

[45]. An adequate therapeutic response to immunosuppression confirms the diagnosis.

HCC development in AIH is less common than other liver diseases. AIH patients with cirrhosis should undergo liver ultrasound in 6-month intervals for HCC screening [46].

\section{Drug-Induced Liver Injury}

DILI is classified as intrinsic (or direct) and idiosyncratic. Intrinsic DILI is dose related and occurs in a large proportion of individuals exposed to the drug (predictable), and onset is within a short time (hours to days). Acetaminophen hepatotoxicity is a prototype of intrinsic DILI and is the most common cause of acute liver failure in the USA and Europe [47]. Idiosyncratic DILI is usually not dose related, is unpredictable, and exhibits a variable latency to onset of days to weeks [48, 49]. Evidence from well-designed studies indicates that drugs work synergistically with other risk factors, age, sex, alcohol intake,
T2DM, and obesity, contributing to pathogenesis and progression of liver disease [50-53]. Phenotypes of DILI and associated medications are shown in Table 2.

Liver biopsy is usually not required for diagnosis. Treatment involves withdrawal of the causative agent. Recovery is usually spontaneous without any specific treatment. The particular therapies are reserved for specific forms of DILI [54].

\section{Hereditary Hemochromatosis}

Hereditary hemochromatosis is one of the most common inheritable genetic disorders. One in 200 individuals in northern Europe is affected by this condition. Polymorphisms in the HFE gene (most frequent homozygotes for the C282Y polymorphism) cause iron overload due to excess iron absorption and induce accumulation in tissues and organs. Without appropriate treatment, excess iron leads to cirrhosis while one-third of patients will develop a primary liver cancer [55]. 


\section{Wilson's Disease}

Wilson's disease in another inherited condition in which defective biliary excretion of copper leads to copper accumulation in the liver and brain. It is a rare autosomal recessive disorder with a frequency of 1 in 30,000. About $3 \%$ of patients present beyond the fourth decade, either with hepatic or neurologic disease. Clinical presentation can vary widely, but most of the patients develop cirrhosis, neuropsychiatric disturbances, and KayserFleischer rings, while some present with the acute liver failure and acute onset of hemolysis [56].

\section{Hepatocellular Carcinoma}

HCC represents about $90 \%$ of primary liver cancers and constitutes a major global health problem. HCC is the sixth most common cancer in the world and the third most frequent cause of cancer-related death globally, while incidence is rapidly rising in last decades [57].

Major risk factors include infections $\mathrm{HCV}$ and $\mathrm{HBV}$, alcohol, and aflatoxin exposure. Only 40\% of patients with HCC are diagnosed at early stages. Patients with cirrhosis are at the highest risk and should undergo liver US for HCC screening in every 6 months. Serological tests including alpha fetoprotein are not currently cost effective. Diagnosis of HCC in cirrhotic patients should be based on noninvasive criteria and/or pathology. Surgical resection is the treatment of choice in patients with HCC arising on a noncirrhotic liver [58].

There are several different algorithms in the treatment of HCC. One of the most widely used is the Barcelona Clinic Liver Cancer (BCLC) system, which classifies patients into 5 stages. For very early-stage HCC or stage 0 single tumor, $<2 \mathrm{~cm}$ (carcinoma in situ), resection is indicated. For very early-stage HCC or stage 0 and for early stage or stage A HCC (no $>3$ nodules, each $<3 \mathrm{~cm}$ ), in the absence of liver disease, LT is the therapy of choice. For stage 0 and stage $A$ in the presence of associated liver diseases, radiofrequency ablation is the therapy of choice. For intermediate or stage B HCC (multinodular), transarterial chemoembolization is recommended. For advanced or stage C HCC (portal invasion, N1, and M1), sorafenib is recommended. For terminal or stage D disease (Child-Pugh C), palliative treatment with supportive care is recommended [59].

Diagnosing benign liver tumors and differentiating in relation to HCC is based on radiological examination, and it is primarily related to the size of the lesion. Lesions
$<1 \mathrm{~cm}$ are monitored by ultrasound at 4 months. For lesions $>1 \mathrm{~cm}$, CT or MR examination should be performed [60].

\section{Conclusion}

CLD is amenable to prevention and treatment, reducing the burden of liver disease and deaths due to endstage liver diseases. Removal of the etiological factors causing liver injury is the most important step in the management of cirrhosis. To prevent complications, patients with CLD need surveillance. Treatment with potent agents for some CLD has beneficial effects in liver function, delays the occurrence of hepatic decompensation, and improves outcome and survival. The integrated approach is needed to achieve the best possible outcomes including the primary care physician, gastroenterologist/ hepatologist, and liver transplant team to closely monitor patients with CLD in order to prevent complication and timely recognition for LT.

\section{Conflict of Interest Statement}

The authors have no conflicts of interest to declare.

\section{Funding Sources}

The authors declare that there were no funding sources in the preparation of data for the manuscript.

\section{Author Contributions}

All the authors contributed equally to the manuscript. Miodrag N. Krstić, Dragana Mijač, Tomica Milosavljević, and Snežana Lukić wrote the article. Ratko S. Tomašević, Jovan M. Krstić, and Milica Stojković Lalošević prepared the concept for the article, analyzed, and corrected the article. All the authors reviewed the final version of the manuscript.

\section{References}

1 GBD 2017 Cirrhosis Collaborators. The global, regional, and national burden of cirrhosis by cause in 195 countries and territories, 1990-2017: a systematic analysis for the global burden of disease study 2017. Lancet Gastroenterol Hepatol. 2020;5:245-66.

2 Asrani SK, Devarbhavi H, Eaton J, Kamath PS. Burden of liver diseases in the world. J Hepatol. 2019;70(1):151-71. 
3 Tapper EB, Parikh ND. Mortality due to cirrhosis and liver cancer in the United States, 1999-2016: observational study. BMJ. 2018; $362: \mathrm{k} 2817$.

4 European Association for the Study of the Liver (EASL), European Association for the Study of Diabetes (EASD), European Association for the Study of Obesity (EASO). EASLEASD-EASO Clinical practice guidelines for the management of non-alcoholic fatty liver disease. J Hepatology. 2016 Jun;6496:1388402.

5 Adams LA, Anstee QM, Tilg H, Targher G. Non-alcoholic fatty liver disease and its relationship with cardiovascular disease and other extrahepatic diseases. Gut. 2017 Jun;66(6) 1138-53.

6 Chalasani N, Younossi Z, Lavine JE, Charlton $\mathrm{M}$, Cusi K, Rinella $\mathrm{M}$, et al. The diagnosis and management of nonalcoholic fatty liver disease: practice guidance from the American association for the study of liver diseases. Hepatology. 2018;67(1):328-57.

7 Loomba R, Lim JK, Patton H, El-Serag HB. AGA clinical practice update on screening and surveillance for hepatocellular carcinoma in patients with nonalcoholic fatty liver disease: expert review. Gastroenterology. 2020 May;158(6):1822-30.

8 Kim D, Kim WR. Nonobese fatty liver disease. Clin Gastroenterol Hepatol. 2017;15(4):47485.

9 Liu YL, Patman GL, Leathart JB, Piguet AC, Burt AD, Dufour JF, et al. Carriage of the PNPLA3 rs738409 $\mathrm{C}>\mathrm{G}$ polymorphism confers an increased risk of non-alcoholic fatty liver disease associated hepatocellular carcinoma. J Hepatol. 2014 Jul;61(1):75-81.

10 Dongiovanni P, Petta S, Maglio C, Fracanzani AL, Pipitone R, Mozzi E, et al. Transmembrane 6 superfamily member 2 gene variant disentangles nonalcoholic steatohepatitis from cardiovascular disease. Hepatology. 2015 Feb;61(2):506-14

11 Sanyal AJ, Chalasani N, Kowdley KV, McCullough A, Diehl AM, Bass NM, et al. Pioglitazone, vitamin $\mathrm{E}$, or placebo for nonalcoholic steatohepatitis. N Engl J Med. 2010 May; 362(18): 1675-85.

12 Kranzler HR, Soyka M. Diagnosis and pharmacotherapy of alcohol use disorder: a review. JAMA. 2018 Aug 28;320(8):815-24.

13 European Association for the Study of the Liver. EASL clinical practice guidelines: management of alcohol-related liver disease. Hepatol. 2018;69:154-81.

14 Johnas DE, Garbutt JC, Amick HR, Brown JM, Brownley KA, Council CL, et al. Behavioral counseling after screening for alcohol misuse in primary care: a systematic review and meta-analysis for the U.S. preventive services task force. Ann Intern Med. 2012 Nov 157(9):645-54

15 Saunders JB, Aasland OG, Babor TF, de la Fuente JR, Grant M. Development of the alcohol use disorders identification test (AUDIT): WHO collaborative project on early de- tection of persons with harmful alcohol consumption-II. Addiction. 1993 Jun;88(6): 791-804.

16 Bush K, Kivlahan DR, McDonell MB, Fihn SD, Bradley KA. The AUDIT alcohol consumption questions (AUDIT-C): an effective brief screening test for problem drinking. Ambulatory care quality improvement project (ACQUIP). Alcohol use disorders identification test. Arch Intern Med. 1998 Sep; 158(16):1789-95

17 Gual A, Segura L, Contel M, Heather N, Colom J. Audit-3 and audit- 4 : effectiveness of two short forms of the alcohol use disorders identification test. Alcohol Alcohol. 2002 Nov-Dec;37(6):591-6.

18 Ewing JA. Detecting alcoholism. The CAGE questionnaire. JAMA. 1984 Oct;252(14): 1905-7.

19 Maddrey WC, Boitnott JK, Bedine MS, Weber FL Jr, Mezey E, White RI Jr. Corticosteroid therapy of alcoholic hepatitis. Gastroenterology. 1978 Aug;75(2):193-9.

20 Dunn W, Jamil LH, Brown LS, Wiesner RH, Kim WR, Menon KV, et al. MELD accurately predicts mortality in patients with alcoholic hepatitis. Hepatology. 2005 Feb;41(2):353-8.

21 Louvet A, Naveau S, Abdelnour M, Ramond MJ, Diaz E, Fartoux L, et al. The Lille model: a new tool for therapeutic strategy in patients with severe alcoholic hepatitis treated with steroids. Hepatology. 2007 Jun;45(6):1348-54

22 Carithers RL Jr, Herlong HF, Diehl AM, Shaw EW, Combes B, Fallon HJ, et al. Methylprednisolone therapy in patients with severe alcoholic hepatitis. A randomized multicenter trial. Ann Intern Med. 1989;110:685-90.

23 Plauth M, Cabré E, Riggio O, Assis-Camilo M, Pirlich M, Kondrup J, et al. ESPEN guidelines on enteral nutrition: liver disease. Clin Nutr. 2006 Apr;25(2):285-94.

24 Kennedy OJ, Roderick P, Buchanan R, Fallowfield JA, Hayes PC, Parkes J. Systematic review with meta-analysis: coffee consumption and the risk of cirrhosis. Aliment Pharmacol Ther. 2016 Mar;43(5):562-74.

25 European Association for the Study of the Liver. EASL recommendations on treatment of hepatitis C: final update of the series. J Hepatology. 2020:1-49.

26 WHO. Global health sector strategy on viral hepatitis 2016-2021. Towards ending viral hepatitis. WHO reference number: WHO/ HIV/2016.06. Available from: https://www. who.int/hepatitis/strategy2016-2021/ghsshep/en/.

27 Belli LS, Berenguer M, Cortesi PA, Facchetti R, Strazzabosco M, Perricone G, et al. Delisting of liver transplant candidates with chronic hepatitis $C$ virus infection after viral eradication: outcome after delisting: a European study. J Hepatol. 2016 Sep;65(3):524-31.

28 Foster GR, Irving WL, Cheung MC, Walker AJ, Hudson BE, Verma S, et al. Impact of direct acting antiviral therapy in patients with chronic hepatitis $\mathrm{C}$ and decompensated cirrhosis. J Hepatol. 2016;64:1224-31.
29 Nahon P, Vo Quang E, Ganne-Carrié N. Stratification of hepatocellular carcinoma risk following $\mathrm{HCV}$ eradication or $\mathrm{HBV}$ control. J Clin Med. 2021 Jan 19;10(2):353.

30 Van der Meer AJ, Feld JJ, Hofer H, Almasio PL, Calvaruso V, Fernández-Rodríguez CM, et al. Risk of cirrhosis-related complications in patients with advanced fibrosis following hepatitis C virus eradication. J Hepatol. 2017 Mar;66(3):485-93.

31 European Association for the Study of the Liver. EASL 2017 clinical practice guidelines on the management of hepatitis $B$ virus infection. J Hepatol. 2017 Aug;67(2):370-98.

32 Hepatitis B vaccines: WHO position paper: July 2017. Wkly Epidemiol Rec. 2017;92(27): 369-92.

33 Mavilia MG, Wu GY. Mechanisms and prevention of vertical transmission in chronic viral hepatitis. J Clin Transl Hepatol. 2017 Jun 28;5(2):119-29.

34 Lok AS, McMahon BJ, Brown RS, Wong JB, Ahmed AT, Farah W, et al. Antiviral therapy for chronic hepatitis B viral infection in adults: a systematic review and meta-analysis. Hepatology. 2016 Jan;63(1):284-306.

35 Papatheodoridis GV, Chan HL, Hansen BE, Janssen HL, Lampertico P. Risk of hepatocellular carcinoma in chronic hepatitis B: assessment and modification with current antiviral therapy. J Hepatol. 2015 Apr;62(4):956-67.

36 European Association for the Study of the Liver. EASL clinical practice guidelines on hepatitis E virus infection. J Hepatol. 2018 Jun;68(6):1256-71

37 Kupferschmidt K. Europe's new hepatitis problem. Science. 2016;353(6302):862-3.

38 Kamar N, Garrouste C, Haagsma EB, Garrigue V, Pischke $\mathrm{S}$, Chauvet $\mathrm{C}$, et al. Factors associated with chronic hepatitis in patients with hepatitis $\mathrm{E}$ virus infection who have received solid organ transplants. Gastroenterology. 2011May;140(5):1481-9.

39 Bendall R, Ellis V, Ijaz S, Ali R, Dalton H. A comparison of two commercially available anti-HEV IgG kits and a re-evaluation of antiHEV IgG seroprevalence data in developed countries. J Med Virol. 2010 May;82(5):799_ 805

40 Kamar N, Izopet J, Tripon S, Bismuth M, Hillaire S, Dumortier J, et al. Ribavirin for chronic hepatitis $\mathrm{E}$ virus infection in transplant recipients. N Engl J Med. 2014 Jun;370(25): 1111-20.

41 Zachou K, Muratori P, Koukoulis GK, Granito A, Gatselis N, Fabbri A, et al. Review article: autoimmune hepatitis: current management and challenges. Aliment Pharmacol Ther. 2013 Oct;38(8):887-913.

42 Czaja AJ, Homburger HA. Autoantibodies in liver disease. Gastroenterology. 2001 Jan; 120(1):239-49.

43 Luth S, Herkel J, Kanzler S, Frenzel C, Galle PR, Dienes HP, et al. Serologic markers compared with liver biopsy for monitoring disease activity in autoimmune hepatitis. J Clin Gastroenterol. 2008 Sep;42(8):926-30. 
44 EASL clinical practice guidelines: autoimmune hepatitis. J Hepatol. 2015 Oct;63(4): 971-1004.

45 Manns MP, Woynarowski M, Kreisel W, Lurie $\mathrm{Y}$, Rust $\mathrm{C}$, Zuckerman E, et al. Budesonide induces remission more effectively than prednisone in a controlled trial of patients with autoimmune hepatitis. Gastroenterology. 2010 Oct;139(4):1198-206.

46 Montano-Loza AJ, Carpenter HA, Czaja AJ. Predictive factors for hepatocellular carcinoma in type 1 autoimmune hepatitis. Am J Gastroenterol. 2008 Aug;103(8):1944-51.

47 Larson AM, Polson J, Fontana RJ, Davern TJ, Lalani E, Hynan LS, et al. Acetaminopheninduced acute liver failure: results of a United States multicenter, prospective study. Hepatology. 2005 Dec;42(6):1364-72.

48 Dara L, Liu ZX, Kaplowitz N. Mechanisms of adaptation and progression in idiosyncratic drug induced liver injury, clinical implications. Liver Int. 2016 Feb;36(2):158-65.

49 Lucena MI, Andrade RJ, Kaplowitz N, GarcíaCortes M, Fernández MC, Romero-Gomez $\mathrm{M}$, et al. Phenotypic characterization of idiosyncratic drug-induced liver injury: the influence of age and sex. Hepatology. 2009 Jun; 49(6):2001-9.
50 Hoofnagle JH, Navarro VJ. Drug-induced liver injury: Icelandic lessons. Gastroenterology. 2013 Jun;144(7):1335-6.

51 Laharie D, Seneschal J, Schaeverbeke T, Doutre MS, Longy-Boursier M, Pellegrin JL, et al. Assessment of liver fibrosis with transient elastography and FibroTest in patients treated with methotrexate for chronic inflammatory diseases: a case-control study. J Hepatol. 2010 Dec;53(6):1035-40.

52 Bruno S, Maisonneuve P, Castellana P, Rotmensz N, Rossi S, Maggioni M, et al. Incidence and risk factors for non-alcoholic steatohepatitis: prospective study of 5408 women enrolled in Italian tamoxifen chemoprevention trial. BMJ. 2005 Apr; 330(7497):932

53 Aithal GP, Watkins PB, Andrade RJ, Larrey $\mathrm{D}$, Molokhia M, Takikawa $\mathrm{H}$, et al. Case definition and phenotype standardization in drug-induced liver injury. Clin Pharmacol Ther. 2011 Jun;89(6):806-15.
54 Fontana RJ, Seeff LB, Andrade RJ, Björnsson E, Day CP, Serrano J, et al. Standardization of nomenclature and causality assessment in drug induced liver injury: summary of a clinical research workshop. Hepatology. 2010 Aug;52(2):730-42.

55 EASL clinical practice guidelines for HFE hemochromatosis. J Hepatol. 2010 Jul;53(1):322.

56 EASL clinical practice guidelines: Wilson's disease. J Hepatol. 2012 Mar;56(3):671-85.

57 World Health Organization. Liver cancer factsheet. Globocan; 2020. Available from: https: //gco.iarc.fr/today/data/factsheets/cancers/ 11-Liver-fact-sheet.pdf.

58 EASL Clinical Practice Guidelines. EASL clinical practice guidelines: management of hepatocellular carcinoma. J Hepatol. $2018 \mathrm{Jul}$; 69(1):182-236.

59 Llovet JM, Zucman-Rossi J, Pikarsky E, Sangro B, Schwartz M, Sherman M, et al. Hepatocellular carcinoma. Nat Rev Dis Primers. 2016 Apr;2:16018.

60 Colombo M. Diagnosis of liver nodules within and outside screening programs. Ann Hepatol. 2015;14(3):304-9. 